\title{
Gold sorption from cyanide media by ANS-3 anionite
}

\author{
Vadym Korovin ${ }^{1, *}$, Yurii Pohorielov ${ }^{1}$, Yurii Shestak $^{1}$, Oleksandr Zontov ${ }^{2}$, and Larysa Zontova ${ }^{2}$ \\ ${ }^{1}$ Institute of Geotechnical Mechanics named by N. Poljakov of National Academy of Sciences of \\ Ukraine, 49005, Dnipro, Simferopolska Str, 2a, Ukraine \\ ${ }^{2}$ Smoly State Enterprise, 51917, Kamianske, Anoshkina Ave., 179, Ukraine
}

\begin{abstract}
Research results were presented for gold sorption from cyanide solutions by ANS-3 macroporous anionite based on styrene-divinyl benzene copolymer. Equilibrium data on gold sorption from a model cyanide solution agreed with the modified Langmuir-Freundlich equation within the studied gold concentrations. Gold stripping results with alkaline cyanide solution were given. Optimal structure of polymer matrix provides high mechanical and osmotic strength of ANS-3 anionite. The anionite is not subjected to an osmotic shock in alkaline solution allowing its application in hydrometallurgical processes including sorption from pulps.
\end{abstract}

\section{Introduction}

Exhaustion of gold-bearing placers, processing of primary ore deposits with low gold content and complicated composition and recoverable materials into the gold processing requires new, more efficient technologies. Currently, sorption methods are widely used for the gold selective recovery Activated carbons and ion-exchange resins are used for this purpose $[1,2]$.

The main industrial technology for gold production involves its leaching by cyanation with further sorption from solutions and pulps, gold stripping by sulphuric solutions of sulphourea with further precipitation from eluates using electrolysis. AM-2B medium base anionite manufactured by Smoly State Enterprise is among the resins widely used in this gold recovery technology.

Considerable simplification of the gold recovery flowsheet is associated with application of weak base anionites, which allow gold elution using alkali liquors. In this case, gold stripping with alkaline solutions is economically and environmentally beneficial over its desertion by acidic reagents. Purolite S992 anionite manufactured by Purolite is among such sorption materials and is regenerated with one treatment with alkaline-cyanide solution at a temperature of $40{ }^{\circ} \mathrm{C}$ to $50{ }^{\circ} \mathrm{C}$ with further water washing [3-5]. ANS-3 anionite manufactured by Smoly State Enterprise is an analogue of this resin.

The present paper deals with the study of gold sorption from model cyanide solutions with ANS-3 anionite.

\footnotetext{
*Corresponding author: sorbent2005@ukr.net
} 


\section{Methods}

\subsection{Materials and reagents}

ANS-3 is a weak base anion exchanger manufactured by Smoly State Enterprise on the basis of macroporous styrene-divinyl benzene copolymer. The anionite features the following parameters: ionic form - free base, total exchange capacity-at least $4.4 \mathrm{mmole} / \mathrm{g}$; moisture retention $-48 \%$ to $52 \%$; particle size in swollen condition -0.8 $\mathrm{mm}$ to $1.4 \mathrm{~mm}$; effective size fraction $-99 \%$; mechanical strength $-99 \%$.

The following reagents were used during experiments: sodium hydroxide, sodium cyanide, hydrochloric acid, dimethyl glyoxime, $0.1 \mathrm{~N}(0.01 \mathrm{~N})$ solution of nickel nitrate, gold ( $99.9 \%$ purity), silver ( $99.9 \%$ purity), metallic copper ( $92 \%$ to $98 \%$ content), zinc oxide. All chemicals used were at least of reagent grade.

\subsection{Experimental technique}

During the anionite preparation for testing, its sieved fraction was soaked in $\mathrm{NaOH} 4 \%$ solution at volumetric ratio solid phase : liquid phase $=1: 4$. In five hours, the anionite was washed with distilled water up to $p H \sim 7$, water was separated. Moisture retention was measured by GOST 10898.1-84.

Gold equilibrium distribution between the anionite and the model gold-containing solution with the composition: $[A u]=3.815 \mathrm{mg} / \mathrm{dm}^{3} ; \quad[A g]=10.76 \mathrm{mg} / \mathrm{dm}^{3} ; \quad[C u]=7.43 \mathrm{mg} / \mathrm{dm}^{3}$; $[Z n]=6.26 \mathrm{mg} / \mathrm{dm}^{3} ; p H=10.23 ;[N a C N]=270 \mathrm{mg} / \mathrm{dm}^{3}$ was studied in static mode by the different portion technique at a temperature of $20 \pm 2{ }^{\circ} \mathrm{C}$ and contact time 24 hours.

To study gold stripping, anionite in $\mathrm{OH}$-form was saturated from the model goldcontaining solution: $[A u]=9.30 \mathrm{mg} / \mathrm{dm}^{3} ; \quad[A g]=1.90 \mathrm{mg} / \mathrm{dm}^{3} ; \quad[C u]=9.03 \mathrm{mg} / \mathrm{dm}^{3}$; $[Z n]=3.36 \mathrm{mg} / \mathrm{dm}^{3} ; p H=10.20 ;[N a C N]=192 \mathrm{mg} / \mathrm{dm}^{3} .5 \mathrm{~cm}^{3}$ of the anionite were contacted with $1.0 \mathrm{dm}^{3}$ of the model solution during 3 days with intermittent agitation at a temperature of $20^{\circ} \mathrm{C}$.

After saturation, the anionite was quantitatively separated from the solution and washed with $100 \mathrm{~cm}^{3}$ of distilled water. Capacity of the saturated anionite was $1.18 \mathrm{mg} / \mathrm{cm}^{3}$.

Gold was stripped with the solution containing $[\mathrm{NaOH}]=5.0 \mathrm{~g} / \mathrm{dm}^{3}$; $[N a C N]=20 \mathrm{~g} / \mathrm{dm}^{3}$. Saturated anionite was sequentially contacted with $25 \mathrm{~cm}^{3}$ of fresh stripping solution. Six stripping stages were carried out with intermittent agitation at a temperature of $60^{\circ} \mathrm{C}$; contact time during each stage was 2 hours.

\subsection{Analytical techniques}

Gold, silver, zinc and copper concentrations in the solution were measured using Saturn-4 atomic-absorption spectrometer. Sodium cyanide concentration in aqueous phase was measured by titration with $0.1 \mathrm{~N}(0.01 \mathrm{~N})$ nickel nitrate solution with dimethyl glyoxime indicator.

Anionite capacity was calculated by the difference of gold concentration in the aqueous phase by the following equation:

$$
q=\frac{\left([A u]_{0}-[A u]_{e q}\right) \cdot V}{m}
$$

where $[A u]_{0}$ and $[A u]_{e q}$ were initial and equilibrium gold concentrations in the aqueous phase, respectively, $V$ was the volume of the solution, and $m$ was the mass of the absolutely dry resin. Anionite capacity in equivalent to absolutely dry resin was calculated taking into account the sample water retention. 


\section{Results and discussion}

Figure 1 illustrates the plot of ANS-3 anionite equilibrium capacity $q$ versus gold equilibrium concentration $[\mathrm{Au}]_{e q}$ during its sorption from the model solution containing $270 \mathrm{mg} / \mathrm{dm}^{3}$ of sodium cyanide and $p H=10.23$.

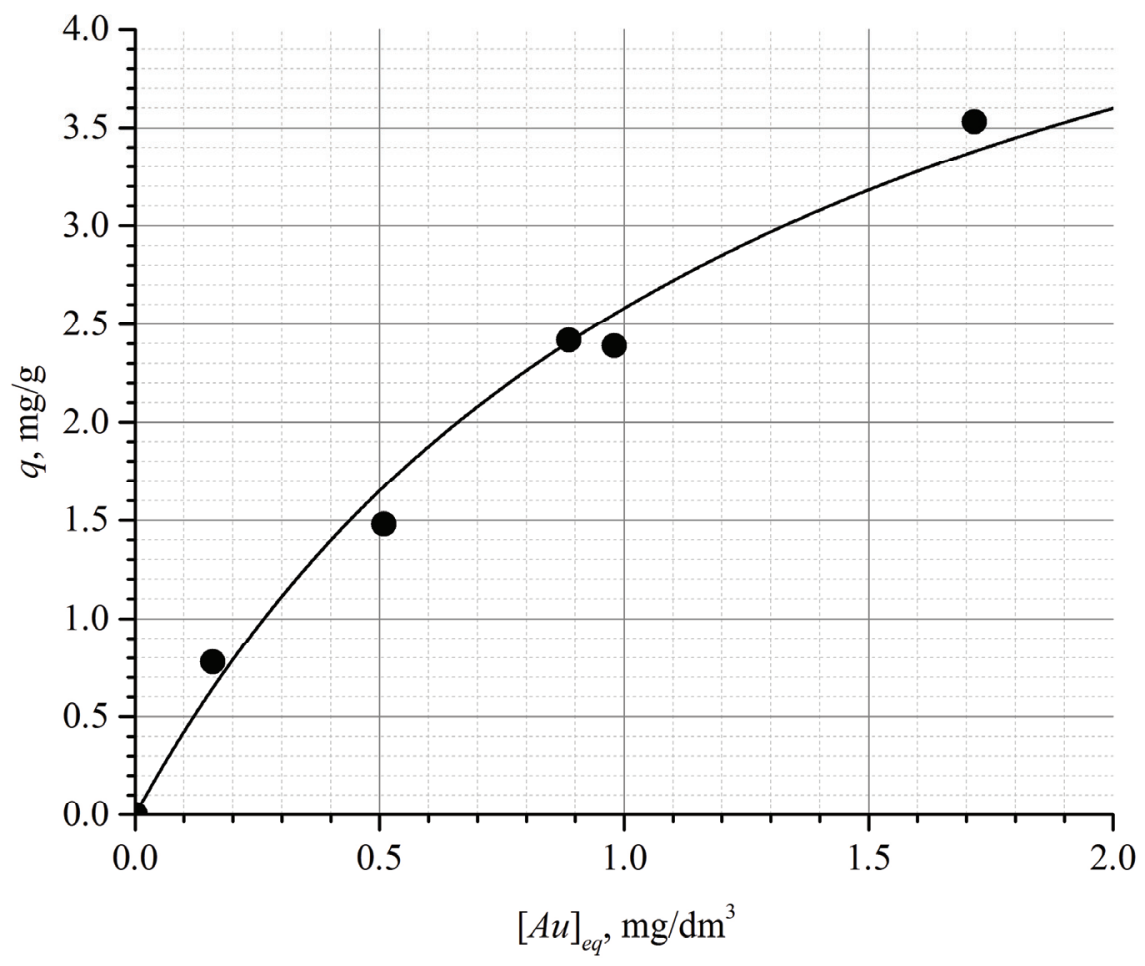

Fig. 1. Gold sorption isotherm by ANS-3 anionite: $(\bullet)$ experimental data, (-) Langmuir-Freundlich fit.

It is seen from the data presented that the anionite has high capacitive characteristics.

Experimental results were fit by the most widely used Freundlich (2) and Langmuir (3) models in a linearized form:

$$
\lg q=\lg K_{F}+\frac{1}{n} \lg [A u]_{e q}
$$

where: $K_{F}$ and $n$ are the Freundlich constant, which represent adsorption capacity and adsorption intensity respectively.

$K_{F}$ and $n$ were defined from a linear plot of $\lg q$ against $\lg [A u]_{e q}$ (Fig. 2);

$$
\frac{[A u]_{e q}}{q}=\frac{[A u]_{e q}}{q_{m}}+\frac{1}{K_{L} \cdot q_{m}}
$$

where $K_{L}$ was the adsorption equilibrium constant, $q_{m}$ was the maximum monolayer adsorption capacity while $q$ and $[A u]_{e q}$ were the equilibrium resin capacity and the equilibrium gold concentration in aqueous phase.

A linearized plot of $[A u]_{e q} / q$ against $[A u]_{e q}$ is shown in Figure 3. 


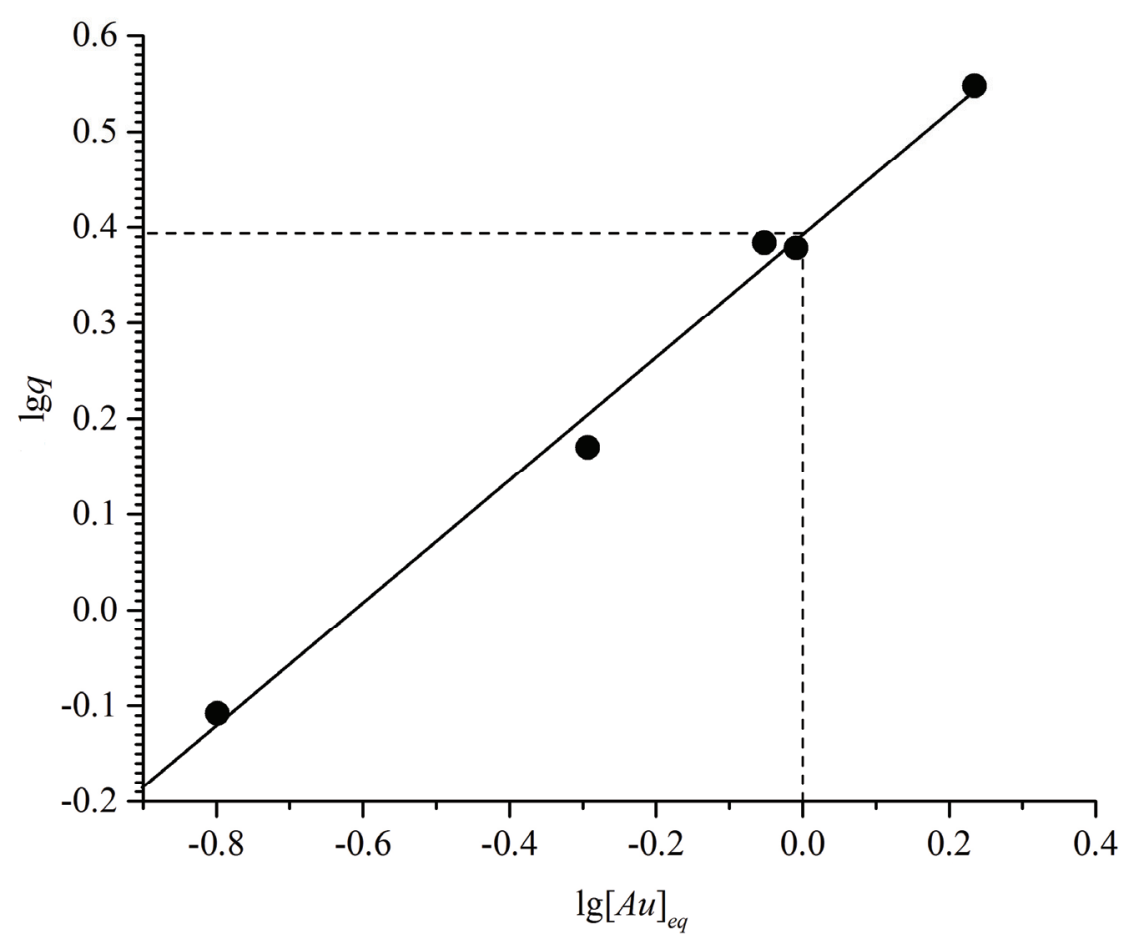

Fig. 2. Linearized Freundlich adsorption isotherm model.

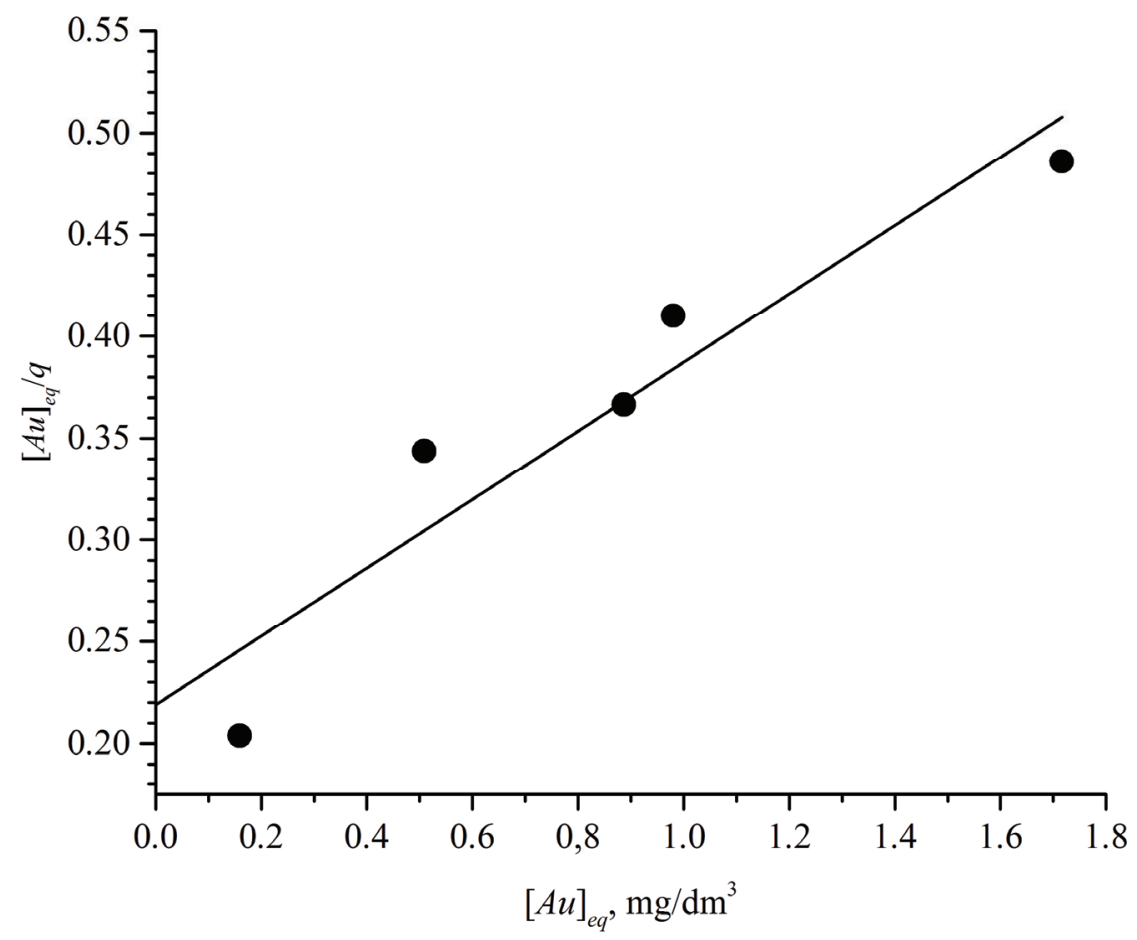

Fig. 3. Linearized Langmuir adsorption isotherm model. 
Experimental data were also processed by the modified Langmuir-Freundlich equation using nonlinear regression analysis. Data processing results are given in Table 1.

Table 1. Parameters of the sorption isotherm equations.

\begin{tabular}{|c|c|c|}
\hline Equation & Parameters & Value \\
\hline \multirow{3}{*}{$\begin{array}{c}\text { Freundlich } \\
q=K_{F} \cdot[A u]_{e q}^{1 / n_{F}}\end{array}$} & Constant $K_{F},(\mathrm{mg} / \mathrm{g}) /\left(\mathrm{mg} / \mathrm{dm}^{3}\right)^{1 / \mathrm{n}}$ & 2.468 \\
\hline & Empiric coefficient $n_{F}$ & 1.558 \\
\hline & Correlation factor $R^{2}$ & 0.9921 \\
\hline \multirow{3}{*}{$q=\frac{\begin{array}{c}\text { Langmuir } \\
q_{m} \cdot K_{L} \cdot[A u]_{e q}\end{array}}{1+K_{L} \cdot[A u]_{e q}}$} & Maximum capacity $q_{m}, \mathrm{mg} / \mathrm{g}$ & 5.939 \\
\hline & Constant $K_{L}, \mathrm{dm}^{3} / \mathrm{mg}$ & 0.7691 \\
\hline & Correlation factor $R^{2}$ & 0.8971 \\
\hline \multirow{3}{*}{$\begin{array}{c}\text { Langmuir - } \\
\text { Freundlich } \\
q_{m} \cdot K_{L F} \cdot[A u]_{e q} n_{L F}\end{array}$} & Maximum capacity $q_{m}, \mathrm{mg} / \mathrm{g}$ & 5.939 \\
\hline & Constant $K_{L F}, \mathrm{dm}^{3} / \mathrm{mg}$ & 0.7691 \\
\hline & Heterogenicity $n_{L F}$ & 1.0 \\
\hline $1+K_{L F} \cdot[A u]_{e q}^{n_{L F}}$ & Correlation factor $R^{2}$ & 0.9999 \\
\hline
\end{tabular}

Within the studied range of gold concentrations $0.15 \mathrm{mg} / \mathrm{dm}^{3}$ to $2.0 \mathrm{mg} / \mathrm{dm}^{3}$, Langmuir and modified Langmuir-Freundlich equations were almost the same. There were the following parameters of the modified Langmuir-Freundlich equation: maximum capacity $q_{m}=5.939 \mathrm{mg} / \mathrm{g}$, constant $K_{L F}=0.7691 \mathrm{dm}^{3} / \mathrm{mg}$.

Figure 4 illustrates results of gold stripping with alkaline cyanide solution in coordinates the number of desorption stages versus gold concentration in desorbate $[A u]$ and gold stripping degree $s$ in percent.

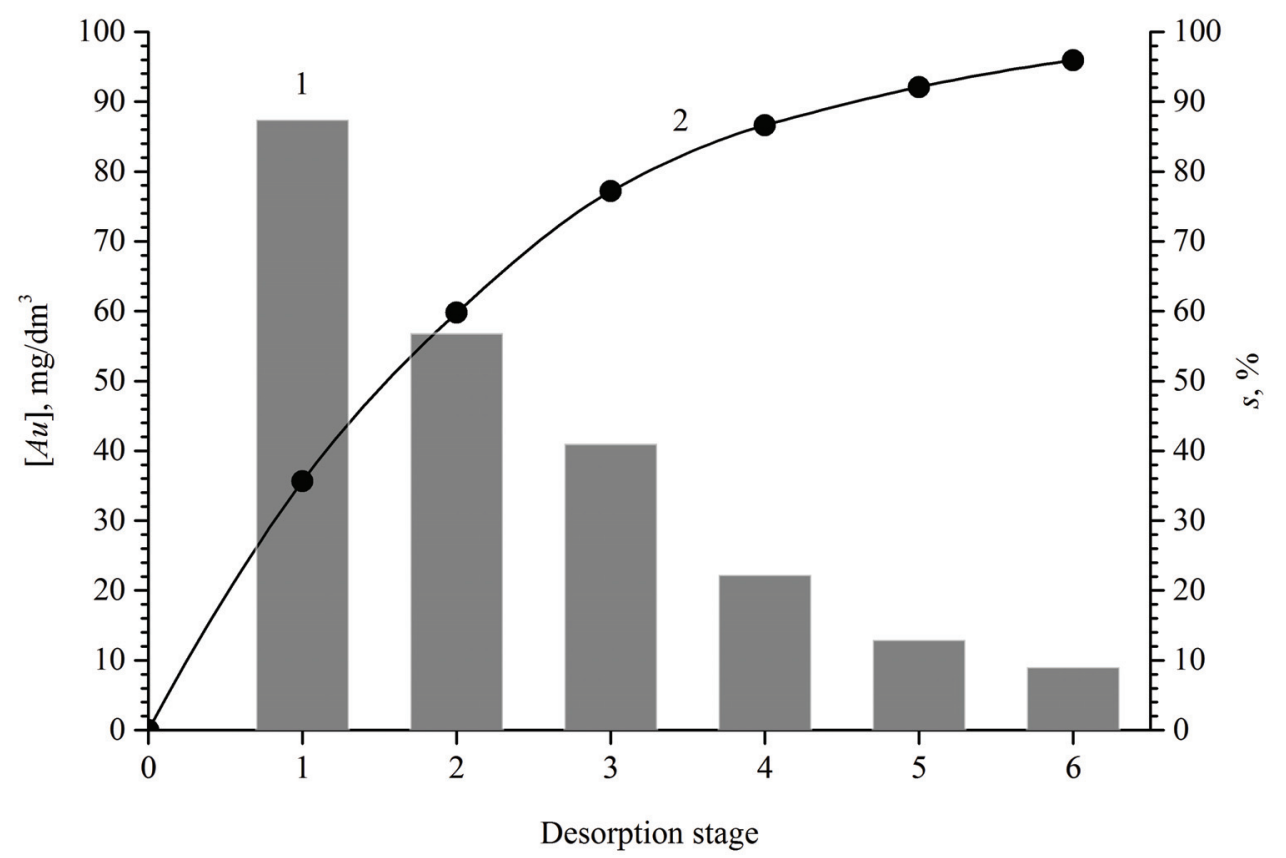

Fig. 4. Gold content in desorbate (1) and its stripping rate (2) versus the number of stripping stages. 
Gold stripping rate was $95.92 \%$ over 6 stages at the gold maximum concentration in desorbate $[A u]=87.42 \mathrm{mg} / \mathrm{dm}^{3}$ at the first stage and its average content in averaged desorbate $[A u]=37.9 \mathrm{mg} / \mathrm{dm}^{3}$. Gold residual concentration in the resin was $0.048 \mathrm{mg} / \mathrm{cm}^{3}$.

\section{Conclusions}

As a result of the study, it was established that equilibrium data on gold sorption from a model cyanide solution agreed with the modified Langmuir-Freundlich equation within the studied gold concentrations.

Gold was efficiently stripped by alkaline cyanide solution.

Optimal structure of polymer matrix provides high mechanical and osmotic strength of ANS-3 anionite. The anionite is not subjected to osmotic shock in alkaline solution allowing its application in hydrometallurgical processes including sorption from pulps.

\section{References}

1. Volkov, V.P. (2014). Sorbcionnye processy deystviushchikh proizvodstv. Moskva: Izdatelskiy dom Ruda i metally

2. Kononova, O.N., Holmogorov, A.G., Kononov, Yu.S. (2018). Sorbcionnoe izvlechenie zolota iz rastvorov $i$ pulp. Himizm processa, selektivnost, tekhnologiya. Moskva: INFRA-M

3. Androsov, A.A., Dmitrienko, V.P., Zavalyuev, A.S., Sidorov, M.E., Shestaev, V.F. (2010). Tekhnologicheskie issledovaniya sorbenta PuroGold na ZIF OAO «Pokrovskiy rudnik», Tsvetnye metally, 9, 37-39

4. Shaposhnikova, E.E., Mansurov, Yu.N. (2014). Hydrometallurgical technology of extraction of gold from fir-tree fraction with PuroGold pitch use on JSC «Pokrovsk mine» International journal of experimental education, 8, 45-49

5. Van Deventer, J., Kotze, M., Yahorava, V. (2012). Alta 2012 Gold Conference, Perth, Australia, 31 May to 1 June 2012, 67-175 